a married man). Our figures represent a conservative estimate of the incidence of recent disruption in close relationships, since only those cases in which the evidence was unequivocal and confirmed by relatives or friends were included.

Disruption of interpersonal relationships was correlated with attempted suicide in the present study (Greer et al., 1966), and a statistical association was also demonstrated between such disruption and parental loss in childhood. The adverse social circumstances and background of attempted suicides, so clearly described by Kessel (1965), pertained in approximately one-half of the present sample. These patients came from broken homes, their suicidal attempts were often preceded by disruption of a close relationship, and a substantial minority were sociopaths (the proportion being more than four times as high as that among patients from intact homes). Thus suicidal behaviour in one group of patients was associated with parental loss, personality disorder, and disruption of interpersonal relationships, and each of the latter two variables was correlated with parental loss. These results provide support for the observations of Kessel (1965), who noted the frequency of parental absence and poor interpersonal relationships among his patients and speculated: "Whether the broken parental home is the root from which stems the disorganized life-pattern, the disorganized marriage ... of ten found in the stories of people who poison themselves."

The remaining half of the present sample came from intact homes, sociopathic personality disturbance was rare, and recent disruption of relationships significantly less common. As we have seen, the patients in this group were older, and schizophrenic and depressive psychoses were more than three times as frequent as among patients from broken homes. It is probable that psychotic illness contributed to suicidal behaviour here, but since only $14 \%$ of the patients from intact homes suffered from functional psychoses it is evident that other, as yet unknown, predisposing factors were operative in this group.

The suicidal patients who had experienced parental loss in childhood and those who came from intact homes showed many similarities. Nevertheless, the circumstances associated with suicidal behaviour differed in each group in several important respects. The present findings indicate the possibility of distinct, though overlapping, subgroups among attempted suicides. The delineation of such categories is of heuristic importance and warrants further investigation. In this connexion it is suggested that studies of larger patient-samples, enabling the use of more sophisticated statistical techniques such as multivariate analysis, should prove fruitful.

\section{Summary}

In a consecutive series of 156 attempted suicides admitted to a general hospital comparisons were made between patients who had suffered parental loss in childhood $(\mathrm{N}=76)$ and those who came from intact homes $(\mathrm{N}=80)$ with regard to a number of variables.

Patients from broken and intact homes were found to $\mathrm{tc}$ similar in terms of sex ratio, marital state, social class, couniry of origin, material circumstances, preceding physical illness, incidence of previous suicidal attempts, social isolation, and seriousness (i.e., medical danger) of the present suicidal attempt.

Statistically significant differences were demonstrated between patients from broken and intact homes in the following respects : (1) age, the group from intact homes included a higher proportion of patients aged 50 and over ; (2) diagnosis-schizophrenic: and psychotic depressive illnesses were more common and sociopathic personality disturbance less common among patients from intact homes than among the group from broken homes ; and (3) disruption of a close interpersonal relationshipthis experience preceded suicidal attempts more often among patients from broken homes than among those from intact homes.

The possibility of two distinct, though overlapping, groups within the present sample of suicidal patients is considered and the need for further studies aimed at identifying subgroups of attempted suicides is stressed.

We are grateful to Dr. D. Liddell, head of the department of psychological medicine, for his advice and guidance. Our thanks are also due to Mrs. R. Badham for secretarial work.

\section{REPERENCES}

American Psychiatric Association (1952). Diagnostic and Statistical Manual of Mental Disorders. Washington.

General Register Office (1960). Classification of Occupations. H.M.S.O. London.

Greer, S., Gunn, J. C., and Koller, K. M. (1966). Brit. med. Y., 2, Kessel, N. (1965). Ibid., 2, 1265.

\title{
Modified Technique for Long-term Endocardial Pacemaking*
}

\author{
M. S. GOTSMAN, M.D., M.R.C.P., M.R.C.P.GLASG., D.T.M.\&H.; W. BECK, M.SC., M.MED., M.R.C.P. \\ L. W. PILLER, F.S.C.T. ; S. C. W. BOSMAN, M.B., CH.B.; C. N. BARNARD, M.D., M.MED., M.S., PH.D., P.A.C.s. \\ V. SCHRIRE, M.D., M.SC., PH.D., F.R.C.P.ED., F.R.C.P., F.A.C.C.
}

Brit. med. 7., 1966, 2, 1357-1360

Transvenous endocardial pacemaking with a subcutaneous implanted generator is now established as a satisfactory method of long-term pacing in patients with complete heart-block (Furman, Schwedel, Robinson, and Hurwitt, 1961 ; Siddons and Davies, 1963 ; Harris, Bluestone, Busby, Davies, Leatham, Siddons, and Sowton, 1965 ; Bluestone, Davies, Harris, Leatham, and Siddons, 1965). In the elderly patient it avoids thoracotomy, the hazards of surgery, and postoperative chest complications.

The transvenous technique, although simple, is still not faultfree. There are mechanical and electronic problems with displacement of the electrode tip and defective pacing, faults in the units or connexions, unexplained rise in endocardia! threshold, and fractured electrode wires. Biological problems such as perforation of the myocardium, cervical and axillary wound breakdown, septicaemia, pulmonary embolism, and ventricular tachycardia also occur (Davies and Siddons, 1965 ; Bluestone et al., 1965 ; Harris et al., 1965).

We have used the transvenous method of endocardial pacing with a generator implanted in the axilla since October 1964.

\footnotetext{
- From the Cardiac Clinic, the Departments of Medicine and Surgery, the University of Capetown and the Cardiovascular-Pulmonary Research Group, supported in the Department of Medicine by the Search Group, supported in the Department 1 U.S.C.I. Catheter Co., Glen Falls, New York.
} 
Our main problems have been generator failure, myocardial perforation, displacement of the tip of the pacemaker electrode wire, and electrode-wire fracture. A septic wound with breakdown of the cervical wound occurred once only (Gotsman, Beck, Barnard, and Schrire, 1966).

Initially we used a two-stage procedure. The first stage consisted in inserting a temporary transvenous pacemaking electrode wire. The procedure was carried out in the catheterization laboratory under local anaesthesia. A No. 5 C52 bipolar pacemaking electrode wire was passed through a superficial vein in the antecubital fossa and wedged in a satisfactory site at the apex of the right ventricle. The wire was then connected to a portable external generator with a variable rate and current output. The second stage was performed two or three days later. The permanent wire and axillary generator were inserted under general anaesthesia in a sterile operating-theatre. The external jugular vein was isolated through a cervical skin incision. A No. $5 \mathrm{C}^{\mathrm{l}} \mathrm{O}^{\mathrm{l}}$ pacemaking electrode wire was then passed to the apex of the right ventricle by means of a portable fluoroscopic image-intensifier. The tip of the wire was wedged at a suitable site where the threshold for pacing was less than 1 volt. An axillary pocket was created for the generator unit by means of a second incision. A loop of pacemaking wire was formed in the neck, and the proximal free end was passed behind the clavicle and attached to the generator. The generator and indifferent electrode were then buried in the axillary pocket. The temporary pacemaking wire was removed 48 hours later if the permanent unit had achieved stable pacing. It was a useful reserve if stable pacing failed and the position of the permanent wire had to be altered.

This method had the advantage of great sterility available in an operating-theatre. Unfortunately the patient needed prolonged anaesthesia for a procedure which often lasted two to three hours. Moreover, if stable pacing failed the technique for readjusting the tip of the pacemaker wire was unsatisfactory. The C50 electrode wire has the same consistency as a conventional cardiac catheter and required a similar method of manipulation. The cervical incision had to be reopened and the loop in the neck dissected free. If this was undertaken during the first week after inserting the wire the tissue planes were still well defined. Later, however, the wire became buried in the dense fibrous tissue, making dissection difficult and tedious. Once the loop had been isolated the tip often had to be withdrawn into the right atrium before being advanced again into the ventricle. This needed considerable rotation and manipulation of the wire, which was fixed at its proximal end where it passed into the axilla.

A fractured electrode wire occurred in four of our patients, and similar experiences were reported elsewhere (Bluestone et al., 1965). Fracture was ascribed to acute angulation in the neck, accentuated by movement of the arm, since it occurred anly when the generator was implanted in the axilla but not when the wire was exteriorized. We therefore modified our technique in two respects. The $\mathrm{C} 50$ wire was replaced by more flexible wire (Elema EMT 570 or $588^{2}$ ). This required gravity control for manipulation, and the patient had to be turned into the lateral position for inserting the wire into the ventricle. The wire also had a larger tip and myocardial perforation was less likely. The generator unit was implanted in the abdomen to avoid the additional stress of arm movements transmitted to the pacemaking wire in the axilla. In the first case in which this technique was employed we found it cumbersome to move the patient on the operating-table; we were also unable to see the stem of the pacemaking wire, as the output of the portable image-intensifier was too weak, and extensive blind dissection was required to pass the pacemaking wire from the neck to the abdomen. The method was therefore simplified on the basis of an approach described by Lagergren, Johansson, Landegren, and Edhag (1965).

The modified technique forms the subject of this report. ${ }^{2}$ Elema-Schonander, Sweden.

\section{Method}

The pacemaking elcctrode wire and the implanted generator unit are inserted as two separate procedures. The first stage consists in inserting the permanent pacemaking wire, which is then exteriorized in the groin or flank and connected to a portable battery-operated external generator. The second stage -implantation of the permanent generator unit-is undertaken 10 days later, when permanent stable pacing is assured. A temporary wire electrode is no longer rcquired.

The first stage-insertion and positioning of the transvenous endocardial wire electrode-is performed in the cardiac cathetcrization laboratory. Local anaesthesia and additional pethidine sedation are used. The external jugular vein is isolated through a small incision in a cervical skin crease. The pacemaking wire (Elema EMT 570 or 588) is then inserted into the vein through a small purse-string suture. This is snugged firmly to avoid bleeding and the vein supported between two stay ligatures. The patient lies on his back and the tip of the wire is guided into the right atrium. The wire is soft and pliable and floats in the blood stream. The tip, made of solid platinum, is heavier and sinks by gravity to the lowest part of the chamber into which it is guided. With the patient on his back, it passes down the dorsal portion of the right atrium and enters the inferior vena cava. Once the tip is opposite the tricuspid valve the patient is turned into the left lateral position and the tip advanced, through the tricuspid valve, to the apex of the right ventricle and wedged. The loop of catheter in the right atrium must be critically positioned and is the key to satisfactory long-term pacing. If it is too gentle the wire may be pulled out during deep inspiration; if too large it may double on itself and pull the tip out, or it may act as a spring and push the tip through the wall of the ventricle. When the operator is satisfied with the position of the wire the purse-string suture in the jugular vein is tightened-acting as a firm anchor-and a second nonabsorbable stay suture is inserted to fix the wire to the deep tissues on the neck.

The next part of the procedure consists in passing the proximal end of the wire through the subcutaneous tissue to the opposite groin or flank. We have made a special needle for this purpose to avoid extensive blind subcutaneous dissection. The hollow thin-walled steel needle is bevelled to form a sharp cutting edge (outer diameter 0.112 in. $(0.28 \mathrm{~mm}$.), inner diameter 0.1 in. $\left(0.25 \mathrm{~mm}\right.$.), size $\left.11 \frac{1}{2} \mathrm{~T}\right)$. The lumen is large enough to accommodate the pacemaking wire threaded through it. It also has a solid obturator with a handle, to avoid damaging the subcutaneous tissues during the tunnelling manœuvre (Fig. 1). The approximate subcutaneous course of the wire is anticipated. The needle is fairly rigid and the subcutaneous surface of the body is curved and convex, so that an intermediate skin incision is usually required. This can be placed in any site, but the lower costal margin or the breast fold is convenient. Local anaesthetic solution is infiltrated at this site and also at the exit site in the flank or groin. Small stab incisions are made in the skin at these sites. The needle is inserted in the intermediate site and passed upwards towards the neck with a rotary cutting action. When it appears in the cervical incision the obturator is removed and the proximal end of the pacemaking wire threaded through the lumen. The needle is then withdrawn and the wire pulled down into the intermediate skin incision. The procedure is then repeated, so that the wire is exteriorized through the exit incision in the flank (Fig. 2).

It is important to keep the needle in the deep subcutaneous tissues during the tunnelling procedure, since advancement is painful when the tip approaches the skin. The average patient tolerates the procedure well, but additional local anaesthesia along the track is required in thin patients. We have also planned the subcutaneous track of the needle to pass in front of the sternoclavicular joint. The arm and clavicle move as a single unit, so that arm movements are transmitted to the 
clavicle. With the wire in front of the sternoclavicular joint it is unaffected by arm movements. The wire should also pass behind the anticipated site of generator implantation so that it can be mobilized when the generator is inserted.

The indifferent electrode (Elema EMT 564) is inserted through a separate skin incision and placed in the subcutaneous tissues of the flank. The threshold for pacing and endocardial resistance is now measured by means of an accurately calibrated external pulse-generator (Corbin-Farnsworth) and a measuring oscilloscope (Tektronix Model 502). If the threshold measurements are satisfactory (less than 1 volt at 2 milliseconds) with stable pacing-that is, every pacemaker impulse initiates a ventricular response-the wire is anchored and the skin incisions are closed. This should be done carefully to prevent displacing or dislodging the electrode wire in the ventricle. A moderate-sized loop of wire without tension is formed in the neck and anchored with a single stay suture. Additional stay sutures produce angulation stresses in the wire when the neck is moved. The loop is valuable for subsequent manipulation if required, and prevents undue traction on the tip if the position of the generator alters. The exit wires (pacemaking and indifferent electrode) are anchored to the skin with silk sutures to prevent traction by the external generator and possible displacement when the dressings are changed.

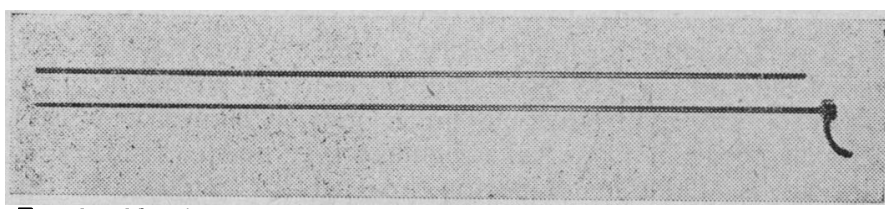

FrG. 1.-Needle with obturator and handle used to thread the pacemaker electrode wire through the subcutaneous tissues from the neck to the flank or groin.

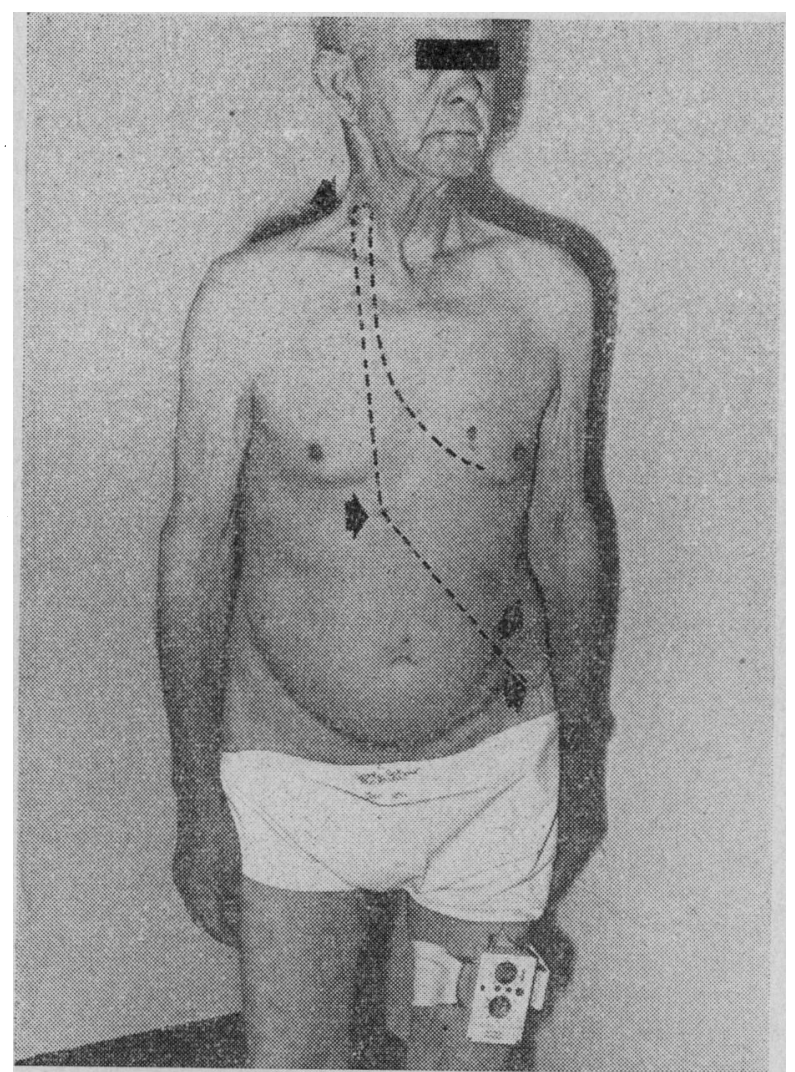

FIG. 2.-Patient with the pacemaking electrode wire exteriorized in the flank. Upper arrow shows the cervical skin incision. Middle arrow points to the intermediate skin incision. Lower two arrows point to two separate skin incisions where the electrode wire and indifferent electrode are exteriorized in the lank. Dotted line indicates the subcutaneous course of the electrode wire.
The patient then returns to the ward for 10 days. This 10-day interval is important, since it tests the stability of pacing. During this period the patient is not confined to bed but allowed to undertake normal ward activity. The threshold for pacing and endocardial circuit resistance is tested every third day. During this period prophylactic cloxacillin and tetracycline are given.

The permanent generator is implanted as a second stage after the 10-day trial of pacing. General anaesthesia is used.

The unit is implanted in front of the rectus sheath in a suitable subcutaneous pocket. The generator (Elema EM 139) and a new indifferent electrode are connected first, and the indifferent electrode is implanted in a suitable position. An intermediate portion of the pacemaking wire is isolated beneath the skin incision. The insulating sheath is removed for $7 \mathrm{~mm}$. at the lower margin of the exposed portion. The wire is then cut and attached to the generator unit.

Prolonged ventricular asystole is an important hazard during the period of change-over. Fortunately this is of short duration and has never lasted more than 30 seconds. The patient receives a supplementary intravenous isoprenaline infusion to prevent asystole, and a second generator is available for emergency use if the change-over is difficult.

With this technique the exteriorized portion of the pacemaking wire and the lower $10 \mathrm{~cm}$. of its subcutaneous portion are not used for permanent pacing, so that contamination of the generator unit and its site of implantation do not occur. At the end of the operation the distal remnant of the wire and the indifferent electrode are removed through the exit incisions.

\section{Results}

The clinical details of the 10 patients on whom this technique has been used are given in the Table. In one patient previous stable pacemaking failed when the electrode wire fractured in the neck. Another patient was transferred from a regional hospital because of unsatisfactory pacing. In a third patient myocardial electrodes inserted elsewhere had become infected. The wires were exteriorized, but in the presence of infection the threshold for pacing had increased to $5 \frac{1}{2}$. volts. Since the maximum output of the external unit was only 6 volts, the margin of safety was too small; an alternative method of pacing was used when the sepsis had improved.

Minor complications occurred and readjustment of the pacemaker tip was required in four of the ten patients. In one a 6-volt pacemaker output produced violent diaphragmatic contraction. The tip was moved to another site where this stimulus did not occur. In a second patient the endocardial threshold for pacing increased to 4 volts. This was probably too high, and the position of the pacemaker tip was altered. In a third patient the pacemaker threshold was 5 volts when the permanent generator was inserted. The position of the tip was not altered and a permanent generator was inserted. Subsequently the wire looped in the right atrium, and occasional intermittent pacing was observed. The position of the tip of the wire was adjusted. In the fourth patient the wire was pulled out of the ventricle by sudden violent extension of the neck during extubation at the end of anaesthesia after the permanent generator had been inserted. The tip of the wire was reinserted into the right ventricle and wedged.

\section{Discussion}

This modified technique for long-term pacing has several advantages.

A different pācemaking electrode wire is used, but its longterm durability and ultimate value can be assessed only when it has given satisfactory service for two years or longer. The 
Clinical Information of Patients Treated by the Modified Method of Long-term Endocardial Pacing

\begin{tabular}{|c|c|c|c|c|c|c|c|c|}
\hline \multirow{2}{*}{$\begin{array}{l}\text { Case } \\
\text { No. }\end{array}$} & \multirow{2}{*}{ Age } & \multirow{2}{*}{ Sex } & \multirow{2}{*}{$\begin{array}{l}\text { Cause of } \\
\text { Heart-Block }\end{array}$} & \multirow{2}{*}{ Indication for Pacing } & \multicolumn{2}{|c|}{ Threshold (Volts) } & \multirow{2}{*}{$\begin{array}{l}\text { Circuit } \\
\text { Resistance } \\
\text { (Ohms) }\end{array}$} & \multirow{2}{*}{ Complication } \\
\hline & & & & & Initial & Final & & \\
\hline $\begin{array}{l}1 \\
2\end{array}$ & $\begin{array}{l}58 \\
74\end{array}$ & $\begin{array}{l}M \\
M\end{array}$ & 二 & $\begin{array}{l}\text { Recurrent syncope } \\
\text { Recurrent syncope. Failure of }\end{array}$ & $\begin{array}{l}0.6 \\
1 \cdot 5\end{array}$ & $\begin{array}{l}1 \cdot 2 \\
1 \cdot 3\end{array}$ & $\begin{array}{l}435 \\
328\end{array}$ & $\begin{array}{l}\text { Fepositioned once } \\
\text { Nil }\end{array}$ \\
\hline 3 & 70 & $\mathrm{M}$ & - & $\begin{array}{l}\text { previous wire } \\
\text { Recurrent syncope }\end{array}$ & 0.5 & $3 \cdot 5$ & 430 & Repositioned after permanent \\
\hline 4 & 58 & $M$ & $\begin{array}{c}\text { Myocardial } \\
\text { infarction }\end{array}$ & $\begin{array}{l}\text { Recurrent syncope. Heart } \\
\text { failure. Fracture of previous }\end{array}$ & $1 \cdot 1$ & $1 \cdots$ & - & $\begin{array}{l}\text { 2nd myocardial infaret between } \\
\text { two stages of impiant }\end{array}$ \\
\hline 5 & 75 & $\mathrm{~F}$ & - & $\begin{array}{l}\text { wire } \\
\text { Intermittent heart block with }\end{array}$ & $1 \cdot 1$ & $2 \cdot 0$ & 320 & Nil \\
\hline 6 & 44 & $\mathrm{~F}$ & ? Toxoplasmosis & $\begin{array}{l}\text { syncope } \\
\text { Recurrent syncope }\end{array}$ & 0.5 & $1 \cdot 6$ & 420 & Repositioned b ause o. \\
\hline 7 & 81 & $M$ & - & Heart failure. Infection in & 0.9 & 0.9 & 355 & Nil \\
\hline $\begin{array}{r}8 \\
9 \\
10\end{array}$ & $\begin{array}{l}81 \\
63 \\
74\end{array}$ & $\begin{array}{l}\mathbf{M} \\
\mathbf{M}\end{array}$ & $\begin{array}{l}\text { Myocardia' infarction } \\
\text { - }\end{array}$ & $\begin{array}{l}\text { Heart failure } \\
\text { Recurrent syncope } \\
\text { Recurrent syncope }\end{array}$ & $\begin{array}{l}0 \cdot 3 \\
0 \cdot 6 \\
0 \cdot 7\end{array}$ & $\begin{array}{l}2 \cdot 5 \\
0 \cdot 8 \\
2 \cdot 2\end{array}$ & $\begin{array}{l}445 \\
326 \\
326\end{array}$ & $\begin{array}{l}\text { Nil } \\
\text { Nil } \\
\text { Repositioned after permanen } \\
\quad \text { unit inserted }\end{array}$ \\
\hline
\end{tabular}

wire used previously was unsatisfactory. The present wire requires little manipulation, since gravity and postural control are used. This avoids unnecessary torsion and manipulation during insertion, and may prevent subsequent fracture from a weakened insulation-covering. The loop in the neck is large and the generator is implanted in the abdomen and not in the axilla. This should avoid transmitted arm movements and repeated angulation stresses.

The pacemaker unit is inserted as a two-stage procedure. Initial temporary transvenous pacing is not required, since the wire inserted at the first stage is used for temporary and permanent pacing. The initial stage is undertaken in the catheterization laboratory. Electronic facilities are available to test the pacemaker wire and endocardial threshold and resistance. Local anaesthesia only is used and the patient is spared prolonged anaesthesia. Patients with a temporary artificial pacemaker and fixed heart rate are sensitive to cutaneous vasodilatation, and cardiac function is often compromised, so that hypotension is common. Although this can be prevented by intravenous phenylephrine, subtle irreversible disturbances of cerebral function may follow.

The long subcutaneous track appears to be a satisfactory barrier to infection provided careful asepsis is practised during insertion of the wire. The subcutaneous needle is safe and produces moderate discomfort only. A trial of pacing is possible, and the electrical behaviour of the implanted wire can be tested before it is attached to the permanent generator. There is often an increase in the threshold for pacing during the first week after a wire is inserted (Davies and Sowton, 1966). By measuring the increases in resistance the long-term behaviour of the generator can be anticipated.

Finally, surgical insertion of the generator is simple, the field is sterile, and only a short period of anaesthesia is required.

Gold, Paneth, and Gibson (1966) have described a similar two-stage procedure in which an antecubital vein and a C50 electrode wire are used. At the second stage the wire is isolated in the axillary vein and the generator implanted in the axilla. Long-term comparison of the two methods will be valuable.

\section{Summary}

A modified technique of permanent transvenous endocardial pacemaking for complete heart-block has been described.

A soft pacemaking electrode wire (Elema EMT 570 or 588 ) is inserted into the external jugular vein and advanced to the apex of the right ventricle under gravity control. With a special needle it is passed subcutaneously and exteriorized in the groin. Stability of pacing is tested for 10 days. If this is satisfactory a permanent abdominal generator is then implanted. We hope that this technique will improve the reliability of transvenous pacemaking.

We thank Dr. J. G. Burger, Superintendent of Groote Schuur Hospital, for permission to publish. We are grateful to Sister J. Riley and her nursing staff for their invaluable assistance in the laboratory, and to the Council for Scientific and Industrial Research and the City Council of Capetown for financial support.

\section{REFERENCES}

Bluestone, R., Davies, G., Harris, A., Leatham, A., and Siddons, $\mathbf{H}$ (1965). Lancet, 2, 307

Davies, J. G., and Siddons, H. (1965). Thorax, 20, 128.

Furman, Sowton, E. (1966). Brit. Heart f., 28, 231. Surgery, 49, 98 .

Surgery, 49, 98.
Gold, R. G., Paneth, M., and Gibson, R. V. (1966). Lancet, 1, 908.

Gotsman, M. S., Beck, W., Barnard, C. N., and Schrire, V. (1966). S. Afr. med.. ., 40,607 .

Harris, A., Bluestone, R., Busby, E., Davies, G., Leatham, A., Siddons, H., and Sowton, E.' (1965). Brit. Heart f., 27, 469.

Lagergren, H., Johansson, L., Landegren, J., and Edhag, O. (1965). $f$. thorac. cardiovasc. Surg.. 50, 710.

Siddons, H., and Davies, J. G. (1963). Lancet, 2, 1204. 